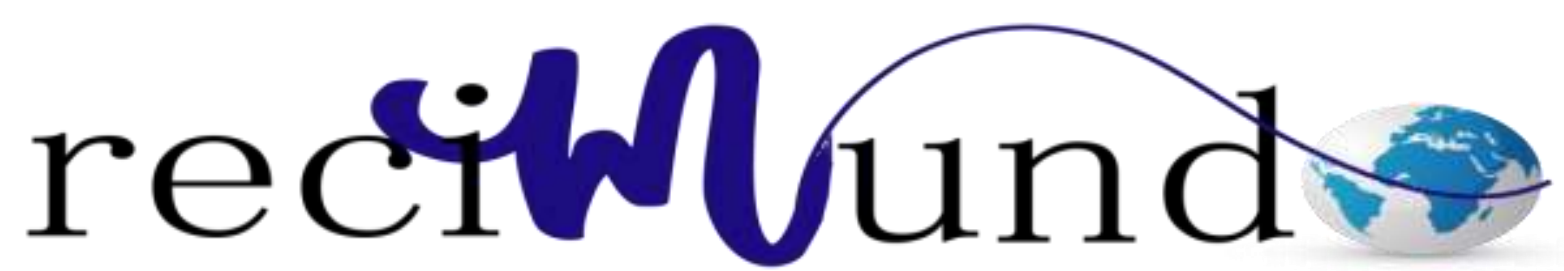

Revista Cientifica Mundo de la Investigación y el Conocimiento

\begin{abstract}
Alyssa Geslenny Bravo Neira ${ }^{\text {a; }}$ Wendy Judith Álvarez Ordoñez ${ }^{\text {b }}$; Erick Gabriel Villacreses Vásquez ${ }^{c}$; Wladimir Alberto Delgado Conforme ${ }^{\mathrm{d}}$
\end{abstract}

Terapias celulares avanzadas en hepatologías: Terapia con células madre en enfermedad hepática en etapa terminal e insuficiencia hepática

Advanced cell therapies in hepatologies: Stem cell therapy in end-stage liver disease and liver failure

Revista Científica Mundo de la Investigación y el Conocimiento. Vol. 3 núm.2, abril, ISSN: 2588-073X, 2019, pp. 752-768

DOI: $10.26820 /$ recimundo/3.(2).abril.2019.752-768

URL: http://www.recimundo.com/index.php/es/article/view/474

Código UNESCO: 3205 Medicina Interna

Tipo de Investigación: Artículo de Revisión

Editorial Saberes del Conocimiento

Recibido: 15/01/2019

Aceptado: 18/02/2019

Publicado: 30/04/2019

Correspondencia: alygbn@gmail.com
a. Médica; alygbn@gmail.com
b. Médica; wenditajao@gmail.com
c. Médico; prince.dmx08@hotmail.com
d. Médico; wladimirroconford@hotmail.com 


\section{Terapias celulares avanzadas en hepatologías: Terapia con células madre en enfermedad hepática en etapa terminal e insuficiencia hepática}

Vol. 3, núm. 2., (2019)

Alyssa Geslenny Bravo Neira; Wendy Judith Álvarez Ordoñez; Erick Gabriel Villacreses

Vásquez; Wladimir Alberto Delgado Conforme

\section{RESUMEN}

Las células hepáticas tienen una capacidad tremenda para multiplicar y regenerar el hígado después de cualquier lesión. Sin embargo, esta capacidad regenerativa en la insuficiencia hepática aguda puede sobrecargar a las células hepáticas y agotarlas en cirrosis con enfermedad hepática en etapa terminal. Actualmente, el trasplante de hígado es el único tratamiento definitivo para estas afecciones del hígado. Sin embargo, debido a la escasez de órganos de donantes muchos pacientes están muriendo mientras están en lista de espera para trasplante de hígado. Como resultado, se ha vuelto importante encontrar una estrategia alternativa para mantener estos pacientes vivos hasta que sus propios hígados se regeneren o los órganos del donante estén disponibles. La medicina regenerativa y el trasplante de células madre pueden ayudar a estos pacientes. Las células madre adultas y las células madre pluripotentes inducidas mostraron buenos resultados cuando se trasplantaron en animales de experimentación. Las células madre diseñadas a partir del propio tejido de los pacientes demostraron ser seguras, así como no inmunogénicas en ensayos clínicos. La presente revisión analizará el estado actual de la terapia con células madre, las células madre disponibles y su aplicación en diferentes enfermedades hepáticas.

Palabras Claves: Células Madres; Falla Hepática; Tratamiento; Cirrosis. 


\title{
Terapias celulares avanzadas en hepatologías: Terapia con células madre en enfermedad hepática en etapa terminal e insuficiencia hepática
}

Vol. 3, núm. 2., (2019)

Alyssa Geslenny Bravo Neira; Wendy Judith Álvarez Ordoñez; Erick Gabriel Villacreses Vásquez; Wladimir Alberto Delgado Conforme

\begin{abstract}
Liver cells have a tremendous capacity to multiply and regenerate the liver after any injury. However, this regenerative capacity in acute liver failure can overload the liver cells and deplete them in cirrhosis with end-stage liver disease. Currently, liver transplantation is the only definitive treatment for these liver conditions. However, due to the shortage of donor organs many patients are dying while on the waiting list for liver transplantation. As a result, it has become important to find an alternative strategy to keep these patients alive until their own livers are regenerated or donor organs are available. Regenerative medicine and stem cell transplantation can help these patients. Adult stem cells and induced pluripotent stem cells showed good results when transplanted into experimental animals. Stem cells designed from patients' own tissue proved to be safe as well as non-immunogenic in clinical trials. The present review will analyze the current status of stem cell therapy, the available stem cells and their application in different liver diseases.
\end{abstract}

Key Words: Stem Cells; Hepatic Failure; Treatment; Cirrhosis. 


\section{Terapias celulares avanzadas en hepatologías: Terapia con células madre en enfermedad hepática en etapa terminal e insuficiencia hepática}

Vol. 3, núm. 2., (2019)

Alyssa Geslenny Bravo Neira; Wendy Judith Álvarez Ordoñez; Erick Gabriel Villacreses

Vásquez; Wladimir Alberto Delgado Conforme

\section{Introducción.}

El hígado es un órgano con notable capacidad regenerativa. Cuando se lesiona una parte del tejido parenquimatoso o una parte del hígado, los hepatocitos en la parte restante del hígado pueden ingresar rápidamente al ciclo celular para reponer y regenerar el hígado con todas sus funciones previas. Sin embargo, cuando hay una pérdida aguda y masiva de tejido hepático, la capacidad regenerativa del hígado no se recupera por completo.La destrucción crónica y la fibrosis en las enfermedades hepáticas crónicas y la cirrosis, por otro lado, pueden agotar completamente la capacidad regenerativa del hígado y deteriorar la capacidad proliferativa de las células hepáticas, lo que resulta en insuficiencia hepática crónica y enfermedad hepática en etapa terminal (Itoh, 2016).

En la actualidad, el trasplante de hígado es la única terapia definitiva para las enfermedades hepáticas en etapa terminal y también para la mayoría de los pacientes con falla hepática. DDLT, el proceso de trasplante de hígados de cadáveres por sus siglas en ingles es más común en los países occidentales, mientras que el LDLT, o el proceso detrasplante de una porción del hígado de un donante vivo al receptor, es el tipo más común de trasplante de hígado en muchos países asiáticos, ya que este procedimiento es más compatible éticamente con la mayoría de las culturas asiáticas (Chen, 2013). Actualmente, el LDLT comprende más del 90\% de las actividades de trasplante de hígado en Asia.

El avance en las técnicas quirúrgicas y la adición de nuevos medicamentos inmunosupresores han mejorado la supervivencia de los injertosy ha traído un éxito tremendo en el campo del trasplante de hígado. Se espera que el período de supervivencia general de 1 año 


\section{Terapias celulares avanzadas en hepatologías: Terapia con células madre en enfermedad hepática en etapa terminal e insuficiencia hepática}

Vol. 3, núm. 2., (2019)

Alyssa Geslenny Bravo Neira; Wendy Judith Álvarez Ordoñez; Erick Gabriel Villacreses Vásquez; Wladimir Alberto Delgado Conforme

para trasplantes de hígado ortotópicos en adultos y niños sea superior al 85\%, con períodos de supervivencia de 5 y 10 años superiores al 70 y 60\%, respectivamente. Sin embargo, actualmente hay una larga lista de espera para el trasplante de hígado. El desajuste existente entre la gran demanda de trasplantes de hígadoy el número de órganos de donantes disponibles destaca la necesidad urgente de estrategias terapéuticas alternativas en pacientes con insuficiencia hepática aguda y crónica. El rápido avance en el campo de la medicina regenerativa y la terapia con células madre está abriendo nuevas ventanas en el tratamiento de las enfermedades hepáticas.

\section{Metodología.}

Para el desarrollo de este proceso investigativo, se plantea como metodología la encaminada hacia una orientación científica particular que se encuentra determinada por la necesidad de indagar en forma precisa y coherente una situación, en tal sentido (Davila, 2015) define la metodología "como aquellos pasos previos que son seleccionados por el investigador para lograr resultados favorables que le ayuden a plantear nuevas ideas".(p.66)

Lo citado por el autor, lleva a entender que el desarrollo de la acción investigativa busca simplemente coordinar acciones enmarcadas en una revisión bibliográfica con el fin de complementar ideas previas relacionadas con terapias celulares avanzadas en hepatologiasa través de una revisión de literatura, para así finalmente elaborar un cuerpo de consideraciones generales que ayuden a ampliar el interés propuesto. 


\section{Terapias celulares avanzadas en hepatologías: Terapia con células madre en enfermedad hepática en etapa terminal e insuficiencia hepática}

Vol. 3, núm. 2., (2019)

Alyssa Geslenny Bravo Neira; Wendy Judith Álvarez Ordoñez; Erick Gabriel Villacreses

Vásquez; Wladimir Alberto Delgado Conforme

Tipo de Investigación

Dentro de toda práctica investigativa, se precisan acciones de carácter metodológico mediante las cuales, se logra conocer y proyectar los eventos posibles que la determinan, así como las características que hacen del acto científico un proceso interactivo ajustado a una realidad posible de ser interpretada. En este sentido, se puede decir, que la presente investigación corresponde al tipo documental, definido por Castro (2016), "se ocupa del estudio de problemas planteados a nivel teórico, la información requerida para abordarlos se encuentra básicamente en materiales impresos, audiovisuales y /o electrónicos”. (p.41).

En consideración a esta definición, la orientación metodológica permitió la oportunidad de cumplir con una serie de actividades inherentes a la revisión y lectura de diversos documentos donde se encontraron ideas explicitas relacionadas con los tópicos encargados de identificar a cada característica insertada en el estudio. Por lo tanto, se realizaron continuas interpretaciones con el claro propósito de revisar aquellas apreciaciones o investigaciones propuestas por diferentes investigadores relacionadas con el tema de interés, para luego dar la respectiva argumentación a los planteamientos, en función a las necesidades encontradas en la indagación.

\section{Fuentes Documentales}

El análisis correspondiente a las características que predomina en el tema seleccionado, llevan a incluir diferentes fuentes documentales encargadas de darle el respectivo apoyo y en ese sentido cumplir con la valoración de los hechos a fin de generar nuevos criterios que sirven de referencia a otros procesos investigativos. Para (CASTRO, 2016) las fuentes documentales 


\section{Terapias celulares avanzadas en hepatologías: Terapia con células madre en enfermedad hepática en etapa terminal e insuficiencia hepática}

Vol. 3, núm. 2., (2019)

Alyssa Geslenny Bravo Neira; Wendy Judith Álvarez Ordoñez; Erick Gabriel Villacreses Vásquez; Wladimir Alberto Delgado Conforme

incorporadas en la investigación documental o bibliográfica, "representa la suma de materiales sistemáticos que son revisados en forma rigurosa y profunda para llegar a un análisis del fenómeno".(p.41). Por lo tanto, se procedió a cumplir con la realización de una lectura previa determinada para encontrar aquellos aspectos estrechamente vinculados con el tema, con el fin de explicar mediante un desarrollo las respectivas apreciaciones generales de importancia.

\section{Técnicas para la Recolección de la Información}

La conducción de la investigación para ser realizada en función a las particularidades que determinan a los estudios documentales, tiene como fin el desarrollo de un conjunto de acciones encargadas de llevar a la selección de técnicas estrechamente vinculadas con las características del estudio. En tal sentido, (Bolívar, 2015), refiere, que es "una técnica particular para aportar ayuda a los procedimientos de selección de las ideas primarias y secundarias”. (p. 71).

Por ello, se procedió a la utilización del subrayado, resúmenes, fichaje, como parte básica para la revisión y selección de los documentos que presentan el contenido teórico. Es decir, que mediante la aplicación de estas técnicas se pudo llegar a recoger informaciones en cuanto a la revisión bibliográfica de los diversos elementos encargados de orientar el proceso de investigación. Tal como lo expresa, (Bolívar, 2015) "las técnicas documentales proporcionan las herramientas esenciales y determinantes para responder a los objetivos formulados y llegar a resultados efectivos" (p. 58). Es decir, para responder con eficiencia a las necesidades investigativas, se introdujeron como técnica de recolección el método inductivo, que hizo posible llevar a cabo una valoración de los hechos de forma particular para llegar a la explicación desde una visión general. 


\section{Terapias celulares avanzadas en hepatologías: Terapia con células madre en enfermedad hepática en etapa terminal e insuficiencia hepática}

Vol. 3, núm. 2., (2019)

Alyssa Geslenny Bravo Neira; Wendy Judith Álvarez Ordoñez; Erick Gabriel Villacreses Vásquez; Wladimir Alberto Delgado Conforme

Asimismo, se emplearon las técnicas de análisis de información para la realización de la investigación que fue ejecutada bajo la dinámica de aplicar diversos elementos encargados de determinar el camino a recorrer por el estudio, según, (Bolívar, 2015) las técnicas de procesamiento de datos en los estudios documentales "son las encargadas de ofrecer al investigador la visión o pasos que debe cumplir durante su ejercicio, cada una de ellas debe estar en correspondencia con el nivel a emplear" (p. 123). Esto indica, que para llevar a cabo el procesamiento de los datos obtenidos una vez aplicado las técnicas seleccionadas, tales como: fichas de resumen, textual, registros descriptivos entre otros, los mismos se deben ajustar al nivel que ha sido seleccionado.

\section{Resultados.}

\section{El papel de la medicina regenerativa en las enfermedades hepáticas agudas y crónicas}

Actualmente, los científicos están tratando de encontrar células madre ideales que puedan regenerar el hígado, reducir los cambios inflamatorios en él, y también puedan reemplazar las células dañadas del hígado.

Las células madre se caracterizan por su capacidad de crecer en muchos tipos diferentes de células en el cuerpo durante la vida temprana y el crecimiento. Células madre puede dividirse ilimitadamente para reponer células y reparar cualquier órgano. Dos características importantes pueden distinguir una célula madre de otras células enel cuerpo. Primero, estas células no son células especializadas y son capaces de renovarse a sí mismas por el proceso de división celular, incluso después permanece inactivo durante mucho tiempo en el cuerpo. En segundo lugar, las 


\section{Terapias celulares avanzadas en hepatologías: Terapia con células madre en enfermedad hepática en etapa terminal e insuficiencia hepática}

Vol. 3, núm. 2., (2019)

Alyssa Geslenny Bravo Neira; Wendy Judith Álvarez Ordoñez; Erick Gabriel Villacreses Vásquez; Wladimir Alberto Delgado Conforme

células madre pueden inducirse para que se conviertan en células específicas de tejidos y órganos

y pueden transportarfunciones especializadas cuando se ponen en condiciones fisiológicas o experimentales específicas. Originalmente las células madre eran de dos tipos: Células madre embrionarias y células madre "somáticas" o "adultas" no embrionarias. En 2006, los científicos pudieron identificar condiciones específicas en las que algunosadultos especializados pueden ser "reprogramados" genéticamente para asumir un estado similar a una célula madre. Este nuevo tipo de células madre se conoce comoCélulas madre inducidas pluripotentes (iPSCs) (Health, 2015).

Las células madre embrionarias son pluripotentes y pueden convertirse en todos los tipos de células del cuerpo. Las células madre embrionarias crecen a partir de células encontradasen el embrión cuando tiene apenas unos días. Además, estas células madre pueden crecer relativamente fácilmente en cultivo. Las células madre adultas son células no diferenciadas y generalmente se encuentran entre células diferenciadas en un tejido u órgano. Las células madre adultas tienen la capacidad de renovarellos mismos y también tienen el potencial de crecer y diferenciarse en la mayoría de los principales tipos de células especializadas del tejido o un órgano. Las células madre adultas participan en la reparación y el mantenimiento del tejido en el que residen (Health, 2015). Los principales tipos de células madre adultasen el que los científicos están realizando investigaciones incluyen células madre hematopoyéticas, células madre mesenquimáticas y células madre pluripotentes inducidas. 


\section{Terapias celulares avanzadas en hepatologías: Terapia con células madre en enfermedad hepática en etapa terminal e insuficiencia hepática}

Vol. 3, núm. 2., (2019)

Alyssa Geslenny Bravo Neira; Wendy Judith Álvarez Ordoñez; Erick Gabriel Villacreses

Vásquez; Wladimir Alberto Delgado Conforme

\section{Células madre hematopoyéticas}

Las células madre adultas pueden diferenciarse en tipos de células que se ven en órganos y tejidos maduros distintos de los que se esperan del linaje que las células suelen seguir. El proceso se considera una diferenciación trans y es una característica de las células madre adultas. Después de recibir células de la médula ósea (células madre hematopoyéticas) de donantes masculinos, se encontró que algunas hembras portaban células hepáticas derivadas de trasplantes células de la médula ósea de sus donantes masculinos (Theise, 2000). Aproximadamente el 0,01\% del total de células en la médula ósea son células madre hematopoyéticas. Estas células madre son conocidas por su plasticidad, que es la capacidad de diferenciarse en linajes no hematopoyéticos como el óvalo hepático, células, hepatocitos y colangiocitos. Se observaron células madre hematopoyéticas en la circulación periférica después de una lesión hepática y también se han encontrado para participar en la reparación del hígado. Se encontraron varios factores de crecimiento que incluyen HGF, factor 1 derivado de células del estroma y sistema MMP9 que influye en la migración de las células hematopoyéticas al hígado después del estrés y la lesión (Shiota, 2016).

Las células madre de la médula ósea del propio paciente se utilizaron como fuente de nuevos hepatocitos para tratar diferentes enfermedades hepáticas en varios ensayos clínicos, y las posibilidades de rechazo son muy bajas en estos experimentos. Recientemente los científicos observaron que el G-CSF puede estimular las células madre de médula ósea para moverse hacia la circulación y después de eso, estas células pueden recogerse fácilmente de la circulación y luego procesarse para trasplante en un receptor. Este método se demostró seguro con efectos de 


\section{Terapias celulares avanzadas en hepatologías: Terapia con células madre en enfermedad hepática en etapa terminal e insuficiencia hepática}

Vol. 3, núm. 2., (2019)

Alyssa Geslenny Bravo Neira; Wendy Judith Álvarez Ordoñez; Erick Gabriel Villacreses Vásquez; Wladimir Alberto Delgado Conforme

larga duración (12 meses) cuando se usó para tratar a pacientes con problemas de alcohol y enfermedades del hígado en etapa terminal relacionadas con la hepatitis B (Theise, 2000).

\section{Células madre mesenquimales}

Las células madre mesenquimales (MSC) se consideran células madre "multipotentes" debido a su capacidad para diferenciarse en una variedad de diferentes tipos de células en el cuerpo. Las MSC se encuentran en el hueso, músculo, cartílago y grasa en los tejidos adultos, así como en la médula ósea, la sangre del cordón umbilical, placenta, tejido hepático y dientes entre diferentes tejidos fetales. Estas células madre tienen propiedades inmunomoduladores que pueden diferenciary reemplazar los hepatocitos dañados, promover la regeneración a partir de hepatocitos residuales y puede inhibir la activación de células estrelladas hepáticas oinducir su apoptosis. Según (Shiota, 2016), el trasplante de MSC dio buenos resultados en diferentes enfermedades hepáticas en modelos experimentales. En experimentos, el tejido adiposo, el líquido amniótico y las MSC derivadas de la médula ósea también resultaron ser eficaces para reducir la lesión hepática aguda y efectos antiinflamatorios en modelos de esteatohepatitis no alcohólica. Los experimentos también revelaron que la fibrosis hepática, la insuficiencia hepática aguda y la enfermedad del hígado graso se pueden tratar en laboratorio utilizando estas células madre. Se necesita más investigación en este campo para averiguar cómo producir células hepáticas a partir de células madre mesenquimales en grandes cantidades y si esto resultará ser un procedimiento seguro en el largo plazo.

\section{Células madre embrionarias}




\section{Terapias celulares avanzadas en hepatologías: Terapia con células madre en enfermedad hepática en etapa terminal e insuficiencia hepática}

Vol. 3, núm. 2., (2019)

Alyssa Geslenny Bravo Neira; Wendy Judith Álvarez Ordoñez; Erick Gabriel Villacreses

Vásquez; Wladimir Alberto Delgado Conforme

El trabajo del Dr. James Thomson condujo a la derivación de células madre embrionarias

humanas en 1998. Se presumió que los tallos embrionarios humanos de las células ayudarían a superar la escasez de tejidos trasplantables y ayudarían a curar muchas enfermedades no tratables. La investigación con células madre embrionarias humanas comenzó a plantear preocupaciones sobre cuestiones éticas de la interrupción del embrión y la incompatibilidad inmune con el donante. Los científicos desarrollaron células madre pluripotentes inducidas, que son células adultas que han sido reprogramadas genéticamentea un estado similar a una célula madre embrionaria al ser forzado a expresar genes y factores importantes para mantener las propiedades definitorias de células madre embrionarias (Health, 2015).

\section{Células madre pluripotentes inducidas}

El desarrollo de la tecnología de células madre pluripotentes inducidas (iPSC) reunió la pluripotencia y el potencial auto renovable de células madre embrionarias. Además, esta tecnología también pudo superar las preocupaciones éticas de la destrucción de embriones porque las iPSC se produjeron a partir de células somáticas in vitro sin usar tejidos embrionarios u ovocitos. El desarrollo de iPSC específicas del paciente para la terapia de reemplazo también fue capaz de eliminar los riesgos de incompatibilidad inmunológica (Berardis, 2015). Las iPSC se produjeron inicialmente en el laboratorio utilizando vector retroviral. Sin embargo, el uso de métodos de reprogramación eficientes dio lugar a la producción de iPSC humanas casi sin riesgo de formación de tumor en el receptor. Las células obtenidas de iPSCs se denominan células similares a hepatocitos y estas células se caracterizan por sus bajos niveles en la producción de 


\section{Terapias celulares avanzadas en hepatologías: Terapia con células madre en enfermedad hepática en etapa terminal e insuficiencia hepática}

Vol. 3, núm. 2., (2019)

Alyssa Geslenny Bravo Neira; Wendy Judith Álvarez Ordoñez; Erick Gabriel Villacreses Vásquez; Wladimir Alberto Delgado Conforme

albúmina, la actividad del citocromo p450 y la actividad del ciclo de la urea, así como su expresión de altos niveles de $\alpha$-fetoproteína.

Células madre pluripotentes inducidas por el hombre y células similares a hepatocitos

Las células similares a hepatocitos (HLC) se diferencian de las células madre pluripotentes inducidas por el hombre. Trasplante de HLCs derivadas de las hiPSC podrían representar una alternativa al trasplante de hígado para el tratamiento de la insuficiencia hepática aguda (ALF), la cirrosis hepática, la hepatitis viraly la corrección de trastornos hepáticos metabólicos hereditarios resultantes de estados genéticamente deficientes. Además, las HLC derivadas de humanos las iPSCs (hiPSCs) de pacientes con afecciones metabólicas hereditarias pueden usarse para modelar enfermedades hepáticas hereditarias. Sin embargo, a largo plazo la seguridad, la tolerabilidad y la eficacia de los tratamientos basados en iPSC, así como su potencial carcinogénico, deben evaluarse rigurosamente, estas células se pueden usar para el tratamiento de enfermedades hepáticas humanas.

Reprogramación directa de los miofibroblastos hepáticos en hepatocitos

En un estudio reciente hecho por (Yu, 2014) que utiliza la inducción del factor de transcripción y el rastreo del destino genético, los científicos desarrollaron hepatocitos inducidos (iHeps) de fibroblastos en modelos de ratón de enfermedad hepática crónica, tuvieron éxito en la conversión de miofibroblastos pro-fibrogénicos en ratones en células similares a hepatocitos capaces de realizar funciones de los hepatocitos. Además, el experimento también mostró disminución de la fibrosis en el hígado dañado donde se generaron estos iHeps. Se necesita más 


\section{Terapias celulares avanzadas en hepatologías: Terapia con células madre en enfermedad hepática en etapa terminal e insuficiencia hepática}

Vol. 3, núm. 2., (2019)

Alyssa Geslenny Bravo Neira; Wendy Judith Álvarez Ordoñez; Erick Gabriel Villacreses

Vásquez; Wladimir Alberto Delgado Conforme

investigación en este campo para encontrar el efecto de este método de reprogramación directa dentro del cuerpo humano y su uso en el tratamiento de diferentes enfermedades crónicas del hígado.

Superando barreras

Inicialmente, existían preocupaciones sobre la necesidad de inmunosupresión después de la terapia con células madre. Como las células iPSC-Hep e iHep son compatibles con los leucocitos humanos y la inmunodepresión personalizada del paciente, si es necesario, debería ser muy mínima. Otra preocupación es acerca del desarrollo de tumores después de la terapia celular. Las células pluripotentes tienen propiedades inherentes para desarrollar teratomas. Sin embargo, las células iHep se producen mediante la reprogramación directa de los fibroblastos sin pasar por la etapa de células madre pluripotentes. Además, también se realizó una rigurosa purificación celular capaz de reducir la contaminación con células madre pluripotentes indiferenciadas. Además, las células madre pluripotentes tienen la capacidad intrínseca que se renueva automáticamente y es capaz de producir grandes cantidades de células Hep necesarias para uso clínico.

Encontrar una ruta adecuada para la entrega de estas células madre fue un problema. En la etapa final de la enfermedad hepática, la arquitectura hepática dañada resulta enel deterioro de la función hepática y el trasplante de células hepáticas en la vena porta de un hígado cirrótico pueden dar lugar a hipertensión portal grave (Song, 2016). Las tecnologías actuales incluyen el uso de "brotes hepáticos", "sistemas de descelularización y recelularización de perfusión" y "sistemas hepáticos de células "fue capaz de resolver muchos de estos problemas [4]. La 


\section{Terapias celulares avanzadas en hepatologías: Terapia con células madre en enfermedad hepática en etapa terminal e insuficiencia hepática}

Vol. 3, núm. 2., (2019)

Alyssa Geslenny Bravo Neira; Wendy Judith Álvarez Ordoñez; Erick Gabriel Villacreses Vásquez; Wladimir Alberto Delgado Conforme

descelularización de órganos es una nueva tecnología en la cual las células de un órgano donante soneliminado, dejando intacta la matriz extracelular y, por lo tanto, produciendo un andamio biológico y arquitectónicamente normal para las células trasplantadas.

Se puede producir un injerto de hígado auxiliar agregando hepatocitos de donante y células no parenquimales en este andamio. Sin embargo, se teme que aunque el trasplante de hepatocitos puede mejorar la función hepática y también puede ayudar a reducir la fibrosis, el tratamiento de la hipertensión portal coexistente y el riesgo de desarrollar carcinoma hepatocelular en el hígado nativo puede continuar existiendo.

El trasplante de células madre y algunas de las terapias con células madre se demostraron eficaces en sujetos humanos y las terapias más nuevas están listas para ensayos clínicos. Al igual que con cualquier otra nueva modalidad de tratamiento, antes de pasar de un banco a otro, la terapia con células madre deberá garantizar que debe haber un mínimo de "riesgos de daño" para el paciente. Debe haber una adecuada selección y reclutamiento de pacientes-sujetos y la toma de decisiones debe ser informada y facilitada por los clínicos siguiendo el protocolo y el proceso de consentimiento adecuados. Además, el médico a cargo del paciente debe tener cuidado de evitar cualquier "error de concepción terapéutica" que pueda dar lugar a una alta e indebida expectativa en el paciente o sujeto. Además, cada estudio clínico debe diseñarse con cuidado, justificarse exhaustivamente y realizarse de manera adecuada para proteger los derechos, los intereses y el bienestar de los sujetos incluidos en el estudio. Además, también debería haberlos esfuerzos para mantener la medicina regenerativa y la terapia con células madre a un costo accesible para los pacientes que los necesitan. 


\section{Terapias celulares avanzadas en hepatologías: Terapia con células madre en enfermedad hepática en etapa terminal e insuficiencia hepática}

Vol. 3, núm. 2., (2019)

Alyssa Geslenny Bravo Neira; Wendy Judith Álvarez Ordoñez; Erick Gabriel Villacreses

Vásquez; Wladimir Alberto Delgado Conforme

\section{Conclusiones.}

Se espera que la medicina regenerativa juegue un papel importante en la recuperación de la función hepática en pacientes con insuficiencia hepática y etapa final de la enfermedad hepática en el futuro. Varias células madre adultas y células madre pluripotentes inducidas mostraron buenos resultados cuando se trasplantaron en animales de experimentación. Las células madre diseñadas a partir del propio tejido de los pacientes demostraron ser seguras, así como no inmunogénicas en ensayos clínicos exitosos.

El trasplante necesitará la producción masiva de células madre. Además, las terapias basadas en células madre deberán pasar por un riguroso escrutinioy repetidos ensayos clínicos antes de que puedan aplicarse en seres humanos. Se espera que los científicos sean capaces de superar todas estas barreras y hacen que el trasplante de células madre sea un tratamiento exitoso, no solo para las fallas hepáticas y las enfermedades hepáticas en etapa terminal, sino también para la cirrosis, la esteatohepatitis no alcohólica y muchas enfermedades hepáticas metabólicas y genéticas.

\section{Bibliografía.}

Berardis, S. (2015). Uso de células madre mesenquimales para tratar la fibrosis hepática: situación actual y perspectivas futuras.

Bolívar, J. (2015). Investigación Documental. México. Pax.

Castro, J. (2016). Técnicas Documentales. México. Limusa.

Chen, C. (2013). Why does living donor liver transplantation flourish in Asia?

Davila, A. (2015). Diccionario de Términos Científicos. Caracas: Editorial Oasis. 


\section{Terapias celulares avanzadas en hepatologías: Terapia con células madre en enfermedad hepática en etapa terminal e insuficiencia hepática}

Vol. 3, núm. 2., (2019)

Alyssa Geslenny Bravo Neira; Wendy Judith Álvarez Ordoñez; Erick Gabriel Villacreses

Vásquez; Wladimir Alberto Delgado Conforme

Health, N. I. (2015). Stem Cell Information, Stem Cell Basics .

Itoh, T. (2016). Stem/progenitor cells in liver regeneration.

Shiota, G. (2016). Progress in stem cell-based therapy for liver disease.

Song, G. (2016). Direct Reprogramming of Hepatic Myofibroblasts into Hepatocytes In Vivo Attenuates Liver Fibrosis.

Theise, N. (2000). Liver from bone marrow in humans.

Yu, Y. (2014). Application of Induced Pluripotent Stem Cells in Liver Diseases. 